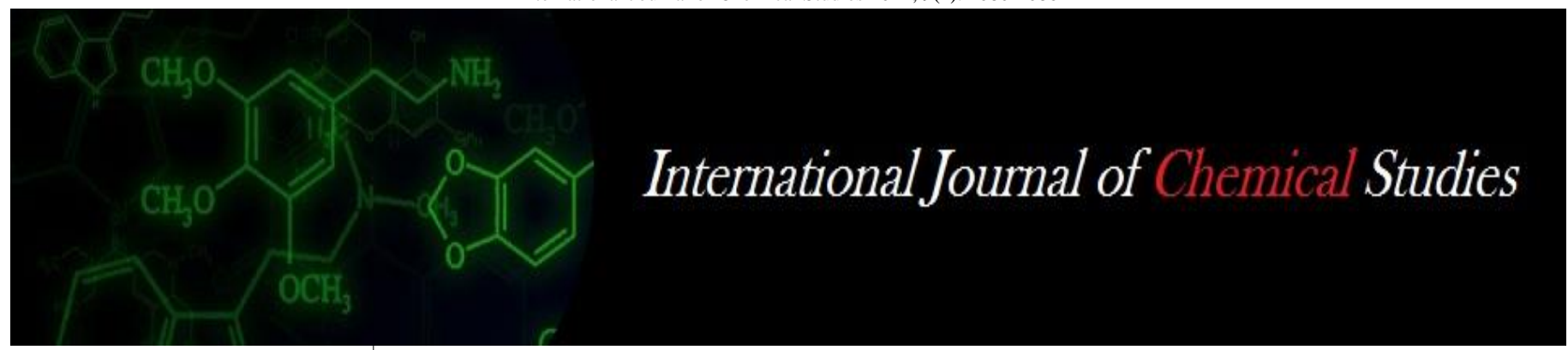

P-ISSN: 2349-8528

E-ISSN: 2321-4902

www.chemijournal.com

IJCS 2021; 9(1): 2080-2086

(C) 2021 IJCS

Received: 09-10-2020

Accepted: 21-12-2020

Kiran Vitalenahalli Rajegowda Department of Food

Biotechnology, Indian Institute of Food Processing Technology Thanjavur, Tamil Nadu, India

Suresh Kumar Kalakandan Department of Food

Biotechnology, Indian Institute of Food Processing Technology Thanjavur, Tamil Nadu, India

Corresponding Author: Suresh Kumar Kalakandan Department of Food Biotechnology, Indian Institute of Food Processing Technology Thanjavur, Tamil Nadu, India

\section{Characterization of custard apple seeds for the separation of prebiotic low molecular weight carbohydrates (LMWC)}

\author{
Kiran Vitalenahalli Rajegowdaa and Suresh Kumar Kalakandan
}

DOI: https://doi.org/10.22271/chemi.2021.v9.i1ac.11531

\begin{abstract}
The concept of waste to wealth is gaining lot of importance in the recent days. In this context, the present study was undertaken to identify the potential prebiotics present in the custard apple seeds. Among the different components identified, the Low Molecular Weight Carbohydrates (LMWC) were chosen for the study and the extraction was performed using Ethanol at three different concentrations $(50 \%, 75 \%$ and $95 \%$ ) and different combination of temperature, time and speed of rotation. The maximum yield of $9.16 \%$ was obtained with $50 \%$ Ethanol, $37{ }^{\circ} \mathrm{C}, 72 \mathrm{~h}$ and $60 \mathrm{rpm}$. The probiotic organism Lactobacillus bulgaricus displayed a positive growth of $7.54 \pm 0.04 \mathrm{log} \mathrm{cfu} / \mathrm{ml}$ on LMWC over a period of 24 hours which confirmed the prebiotic functionality of LMWC. Scanning Electron Microscopy and FTIR analysis were done to confirm the morphological characteristics. Therefore, all the results obtained showed that LMWC can be used as potential prebiotics in the food industry and the commercial utilization of custard apple seeds.
\end{abstract}

Keywords: Custard apple, low molecular weight sugars, extraction, prebiotics

\section{Introduction}

The sugar apple or sweet sop (Annona squamosa), commonly called as Sitaphal in traditional language, and is the fruit of Annonaceae family is a native of tropical America and West Indies. The fruit is nearly spherical to oval in shape with thick rind consisting of knobby segments in which the seeds are surrounded by the pulp (Morton, 1987) ${ }^{[16]}$. The pulp of the fruit is creamy white, fragrant and sweet in taste which will be adhered to seeds forming individual segments arranged in a uniform layer around the core of the fruit. The number of seeds may vary from 20-40 depending upon the variety of the fruit. According to Indiastat (2019), the total production in India was 3,38,000 tonnes over an area of 40,000 Hectares. Out of this, significant amount of the fruits are used for preparation of variety of products such as ice cream, milk shakes and other sweets. The components which remain are the seeds and the rind of the fruit. They are considered as the rich carbon source and may pose the risk of pollution if not handled properly. The custard apple seeds are usually disposed and/or they are used as a planting material. The custard apple seeds are viewed as a rich source for the extraction of essential oil (Lokhande et al., 2013) ${ }^{[10]}$. The utilization of custard apple seeds as a low cost material for the extraction of various prebiotic components is gaining a lot of importance in recent days (Pallavi et al., 2017) ${ }^{[20] .}$

Carbohydrates are widely distributed in a variety of plants and animals as discrete molecules of low-molecular weight or as polymers, the molecular weight of which will be more than one million in certain cases. Plants synthesize these sugars by photosynthesis from carbon dioxide and water. Simple sugars can be a potential prebiotic due to their low molecular weight which will take a fairly longer time to get digested in the body. Prebiotics are the components of the food which cannot be digested in the body that will affect the host cells beneficially by selectively stimulating the growth and/or activity of one or more number of bacteria in the colon" (Gibson \& Roberfroid, 1995) ${ }^{[4]}$. The characteristics of prebiotics are - (a) resistance to hydrolysis by mammalian enzymes, gastric acidity and gastrointestinal absorption; (b) fermentation by the intestinal microorganisms; (c) stimulating the selective growth and/or activity of intestinal microflora associated with health and well-being of the human; (d) 
enhancing the absorption of minerals (Scholz-Ahrens et al., 2001, 2007) [23, 22]. Chemically, these are the indigestible oligo- and polysaccharides by the human digestive system and reach the intestine to stimulate the growth of beneficial bacteria and inhibit the growth of harmful ones. Lactobacillus and Bifidobacteria that share a positive relationship with human host are considered to be beneficial and hence referred as "probiotics". Since the prebiotic components acts as energy source for probiotics and allow increase in their selective growth, they ensure a competitive advantage over the harmful bacteria like S.aureus and E.coli.

With the intention of identifying the natural or the indigenous sources for the presence of prebiotic components, the present study was taken up based on these lines. Custard Apple is considered as a wonder fruit, super fruit due to its wide range of therapeutic and medicinal properties (Jamkhande et al., 2014; Jamkhande \& Wattamwar, 2015) ${ }^{[8,7]}$. The main thrust is given with an intention of making a proper use of the underutilized seasonal fruit in India which is mostly consumed as fresh and not processed. The present study was focused mainly on the utilization of the seeds which are present in a considerable number in the fruit, which are usually thrown away. The experimental study was made using the D-optimal mixture design, which is multi factor design in order to extract the Low Molecular Weight Carbohydrates from the Custard Apple seeds. The extraction was performed using ethanol at three different concentrations of 50\%, $75 \%$ and $95 \%$ in order to obtain the maximum yield of LMWC. The factors used in the design are the Concentration of the ethanol, Extraction temperature, Time of extraction and the Speed of rotation (rpm) of the shaking incubator. The study was majorly focused on identifying the extent of recovery of the LMWC from the custard apple seeds so that the potential components present in the seeds can be utilized for the formulation of wide range of functional and therapeutic foods which will help in boosting the immune strength and disease resistance capacity of the human beings.

\section{Materials and Methods \\ 2.1 Materials}

Fresh, matured Custard apple (Annona squamosa) fruits were procured from Amruthabhoomi natural and organic products Ltd. Chamarajanagar, Karnataka, India. The pulp, peel and seeds were separated manually. The seeds are then washed with water and air dried at $130^{\circ} \mathrm{C}$ for $15 \mathrm{~min}$. The outer shells of the seeds were removed by mechanical pressure. The seeds were then made into uniform granule sized powder of $500 \mu \mathrm{m}$ using electronic pulverizer (Pulverisette 14, FRISTSCH Germany). The fine powder was then stored in air tight bags to prevent the absorption of moisture.

\subsection{Proximate Analysis of the Custard Apple seed powder}

The proximate analysis of the custard apple seed powder was conducted as per the AOAC approved methods. Based on the literature study and the initial trials conducted, the presence of LMWC in the seeds was confirmed and further studies were carried out.

\subsection{Extraction and Purification}

\subsubsection{Sample preparation for extraction}

The custard apple seeds were defatted in hexane (B.P $66^{\circ} \mathrm{C}-$ $68^{\circ} \mathrm{C}$ ) in the solid-to-liquid ratio of $4: 100 \mathrm{~g} / \mathrm{ml}$ for $4 \mathrm{~h}$ and the defatted powder was dried and kept in air tight bags until further use.

\subsubsection{Extraction of LMWC}

LMWC were extracted from the seeds by slight modification of the method followed by Moongngarm et al., $2011^{[15]}$. Ethanol assisted extraction was followed for the separation of LMWC from custard apple seed powder with continuous shaking in the shaking incubator. Extraction was carried out using three different concentration of ethanol at $50 \% \mathrm{v} / \mathrm{v}, 75 \%$ $\mathrm{v} / \mathrm{v}$ and $95 \% \mathrm{v} / \mathrm{v}$ at a constant temperature of $37^{\circ} \mathrm{C}$. Treatment time was increased gradually with constant interval from $24 \mathrm{~h}$, $36 \mathrm{~h}, 48 \mathrm{~h}$ to $72 \mathrm{~h}$ with four different rotational speeds of 60 , 120, 180 and $240 \mathrm{rpm}$.

\subsubsection{Purification of extracted LMWC}

The $\mathrm{pH}$ of the solution was adjusted to 6.8 using $1 \mathrm{M} \mathrm{NaOH}$ as per the method followed by (Moongngarm et al., 2011) ${ }^{[15]}$. The samples were filtered using a muslin cloth and the filtrate was obtained. The solvent in the filtrate was evaporated in a continuous rotary evaporator (IKA, RV 10 Digital) with the vacuum range of $760 \mathrm{~mm} \mathrm{Hg}$ at the speed of rotation of 135 rpm at a temperature of $72^{\circ} \mathrm{C}$.

\subsubsection{Freeze drying}

The LMWC extract was freeze dried in a lyophilizer (Lark lyophilize) operating at a vacuum of $1 \mathrm{~mm} \mathrm{Hg}$ for $72 \mathrm{hrs}$. The dried sample was stored in an air tight bottle and stored at a temperature of $-18{ }^{\circ} \mathrm{C}$ until further use (White \& Cakebread, 1966) ${ }^{[28]}$.

\subsection{Experimental Design for the extraction of LMWC}

Ethanol assisted LMWC extraction was carried out using Brunswick Scientific shaking incubator with the speed ranging from 60-240 rpm. The defatted custard apple seed powder was subjected to extraction with a 1:25 (w/v) sample/solution ratio at different concentration of $50 \%, 75 \%$ and $95 \%$ ethanol and temperatures $\left(30,40,50\right.$ and $\left.60^{\circ} \mathrm{C}\right)$ in the time range of 24-72 hours. All experiments were conducted in triplicates and at the end of each trial, the samples were taken periodically and subjected to rotary evaporation and freeze drying and the reducing sugar content was measured by DNS method using UV-Spectrophotometer at 510nm (Pallavi et al., 2017) ${ }^{[20]}$.

\subsection{Modelling of Ethanol-assisted LMWC extraction}

Ethanol assisted LMWC extraction kinetics was fitted by nonlinear regression using mass transfer mathematical model for the development of a generalized model for the extraction of LMWC from custard apple seed powder. The extraction of LMWC from Custard apple seeds involves the measurement of overall mass transfer coefficient $\left(\mathrm{K}_{\mathrm{L}} \mathrm{a} / \mathrm{V}\right)$ across an external surface area a $\left(\mathrm{m}^{2}\right)$ at any time $\mathrm{t}$ and at saturation conditions. Maximum extractable LMWC \% (C) was obtained by three repeated continuous extractions from the sample. However, the yield of all the extraction process was recorded and the extraction kinetics was performed using MATLAB R2019 by fitting first order equation.

$\mathrm{C}=\mathrm{C}_{\mathrm{S}}\left\{1-\exp \left(-\mathrm{K}_{\mathrm{L}} \mathrm{a}\right) \mathrm{t} / \mathrm{V}\right\}$

Where,

$\mathrm{C}(\mathrm{g} / 100 \mathrm{~g})=$ Concentration of LMWC in the solvent at any time $\mathrm{t}$

$\mathrm{C}_{\mathrm{S}}(\mathrm{g} / 100 \mathrm{~g})=$ Concentration of LMWC in the solvent at saturation conditions

$\mathrm{K}_{\mathrm{L}}\left(\mathrm{min}^{-1}\right)=$ overall mass transfer coefficient at a surface of area $\mathrm{a}\left(\mathrm{m}^{2}\right)$ and volume $\mathrm{v}\left(\mathrm{m}^{3}\right)$ 


\subsection{Estimation of the Prebiotic activity of the LMWC}

The Probiotic cultures selected for studying the activity were Lactobacillus bulgaricus isolated from yoghurt and confirmed positive through Gram's staining and hydrogen peroxide test. Staphylococcus aureus (NCTC 3750) was used as a negative control in the study. For the determination of prebiotic activity, cultures of L. bulgaricus grown on MRS broth $\left(37^{\circ} \mathrm{C}\right.$, anaerobic) and $S$. aureus (NCTC 3750$)\left(37^{\circ} \mathrm{C}\right.$, aerobic) grown on Nutrient broth were supplemented with $1 \%$ glucose and $1 \%$ LMWC for $24 \mathrm{hrs}$ and the growth count were enumerated by using spread plate technique after appropriate serial dilutions on MRS agar for L.bulgaricus and Nutrient agar for S.aureus. The numbers of colony forming units (cfu) on the plates were enumerated using a colony counter (Lapiz colony counter).

The prebiotic activity scores of LMWC were determined according to (Huebner et al., 2007). Prebiotic Activity Score $(\mathrm{PAS})=\{$ (probiotic $\log \mathrm{cfu} / \mathrm{ml}$ on the prebiotic at $24 \mathrm{~h}-$ probiotic $\log \mathrm{cfu} / \mathrm{ml}$ on prebiotic at $0 \mathrm{~h}$ ) / (probiotic log $\mathrm{cfu} / \mathrm{ml}$ on glucose at $24 \mathrm{~h}$ - probiotic log cfu/ml on glucose at $0 \mathrm{~h})\}-$ $\{$ (enteric $\log \mathrm{cfu} / \mathrm{ml}$ on the prebiotic at $24 \mathrm{~h}-$ enteric $\log$ $\mathrm{cfu} / \mathrm{ml}$ on the prebiotic at $0 \mathrm{~h}$ ) / (enteric $\log \mathrm{cfu} / \mathrm{ml}$ on glucose at $24 \mathrm{~h}$ - enteric log cfu/ml on glucose at $0 \mathrm{~h})\}$.

\subsection{Methods for the evaluation of Quality Parameters 1) FTIR Spectrum}

Fourier Transform Infrared Spectroscopy (FT-IR) was used for characterization of custard apple seed powder and purified LMWC structure (Černá et al., 2003; Shaltout et al., 2011) ${ }^{[1,}$ ${ }^{24]}$. IR spectra were collected using FT-IR Spectrophotometer, PerkinElmer, USA. The curves were produced at the resolution of $4 \mathrm{~cm}^{-1}$ with 16 scans ranging from $400-4000$ $\mathrm{cm}^{-1}$.

\section{2) Scanning electron microscopy}

Morphological observations of the Custard apple seed powder and the LMWC obtained after extraction were obtained by Scanning Electron Microscopy. Microscopy was carried out with (VEGA3 TESCAN, Czech Republic) model system at 10 $\mathrm{kV}$ accelerating voltage with $1.00 \mathrm{KX}$ magnification (Parate et al., 1986) ${ }^{[21]}$.

\section{3) Statistical data analysis}

All the experimental data was obtained in triplicates and analyzed using IBM SPSS 9.0 for analysis of variance (ANOVA).

\section{Results and Discussions}

\subsection{Proximate composition of the custard apple seeds}

Custard apple seeds were chosen for the current study to identify the potential prebiotics present in them under the perspective of waste to wealth concept. A detailed study was conducted in order to identify the composition of the Custard apple seeds. All studies were made in triplicates based on the reports available on the proximate composition of the peel and seed with respect to foreign matter, moisture content and ash (Fontana Jr \& Carter, 2020; Jamkhande \& Wattamwar, 2015; Pallavi et al., 2017; Shardul et al., 2013) ${ }^{[2,20,8,25]}$. The results of the proximate composition are presented in Table 1.

\subsection{Extraction kinetics of LMWC}

Extraction processes are governed by the mass transfer principles and the separation of LMWC is a function of: a) Extraction through direct interaction of the cell matrix with the solvent, resulting in the leaching of the compounds into the solvent; b) Evaporation of the solvent by heating up to its boiling point retaining the extracted compound (Wichienchot et al., 2011) ${ }^{[29]}$. In order to better understand the extraction process, kinetics of extraction was performed using a single step model. The constant used to explain the extraction process was overall mass transfer Coefficient $\left(\mathrm{K}_{\mathrm{L}}\right)$ as given in equation 1. The results obtained are given in Figure 1.

\subsection{Estimation of Prebiotic Potential of LMWC}

The ability of the substrate to get metabolized effectively by the beneficial bacteria in comparison to the harmful bacteria is the major factor to identify the substrate as a prebiotic. The quantification of the Prebiotic potential of the substrates can be done by determining the Prebiotic Activity Score (Huebner et al., 2007; Pallavi et al., 2017) ${ }^{[20]}$. The LMWC fractions in the purest form are directly added as an active carbon source in the bacterial growth medium. The structural-functional relationship was elucidated to find out how they could affect the prebiotic activity when they are separated from the food matrix. The growth of bacteria on glucose was used as a standard for comparison.

From the bacterial cell growth observed (Table 3), it can be assumed that the LMWC are efficiently utilized by $L$. bulgaricus than that of $S$. aureus. The data was used to calculate the prebiotic activity score. The prebiotic Activity Score (PAS) of LMWC was 0.21. A positive Prebiotic Activity Score indicated that the substrates are effectively utilized by the probiotic than glucose and are therefore considered as potential prebiotics. A negative score would indicate that the components are being underutilized by the probiotic or are better utilized by the pathogenic strains. Even though the rate of growth of L. bulgaricus was much higher than that of $S$. aureus, the limited amount of available LMWC as a carbon source into the medium might have affected the duration of log phase and hence, the prebiotic activity score. Therefore, the lower yield of LMWC obtained may probably indicate the low prebiotic activity score of the LMWC.

\subsection{Methods for the Evaluation of Quality Parameters 3.4.1 Structural Analysis}

FTIR spectra analysis of the custard apple seed powder and the extracted LMWC from the custard apple seeds were done to identify the sugars, functional groups and to compare the yield of sugars with the raw seed powder used as a control. The wavelength of the spectrum from $950 \mathrm{~cm}^{-1}$ to $1200 \mathrm{~cm}^{-1}$ are known as the fingerprint region of the carbohydrates since it depicts the presence of major functional groups of the monosaccharides and polysaccharides (Černá et al., 2003; Shaltout et al., 2011) ${ }^{[1,24]}$. The carbohydrates in the sample were retained after subjecting it to extraction at different treatment conditions(Figure 2). The absorption band from 1011 to $1120 \mathrm{~cm}^{-1}$ corresponds to the C-O-C glycosidic ring bond stretching, $\mathrm{O}-\mathrm{H}$ bending and stretching of the $\mathrm{C}-\mathrm{O}$ bond in $\mathrm{COOH}$. The region was same for both the seed powder and LMWC extract. The region between 890 to $1000 \mathrm{~cm}^{-1}$ represents low and moderate intensity bands of C-C skeletal vibrations. Thus, the data obtained from FTIR shows the similar pattern between both samples and corresponds to the presence of LMWC sugars.

\subsubsection{Scanning Electron Microscopic Imaging}

SEM images for the Custard Apple Seed Powder and the extracted LMWC was shown in Figure.3. Different morphological changes in the powder surface were seen with the increase in the magnification. Figure 3 (A), (B) and (C) 
are that of the custard apple seed powder under different magnifications of X150, X700 and X1000 clearly indicated that the particles were agglomerates due to high hygroscopicity of the sugars in the seed powder. In figure $3 \mathrm{D}$, $3 \mathrm{E}$ and $3 \mathrm{~F}$ were the freeze dried LMWC extract under $\mathrm{X} 10000, \mathrm{X} 12000$ and X20,000 with more compact and amorphous structures. The particles were found to be stiff and highly rigid morphology was seen. From the observation of the SEM, the particles were tending to be appeared as amorphous surfaces because of the binding of the particles. The results were in good agreement with the work done by (Parate et al., 1986) ${ }^{[21]}$.
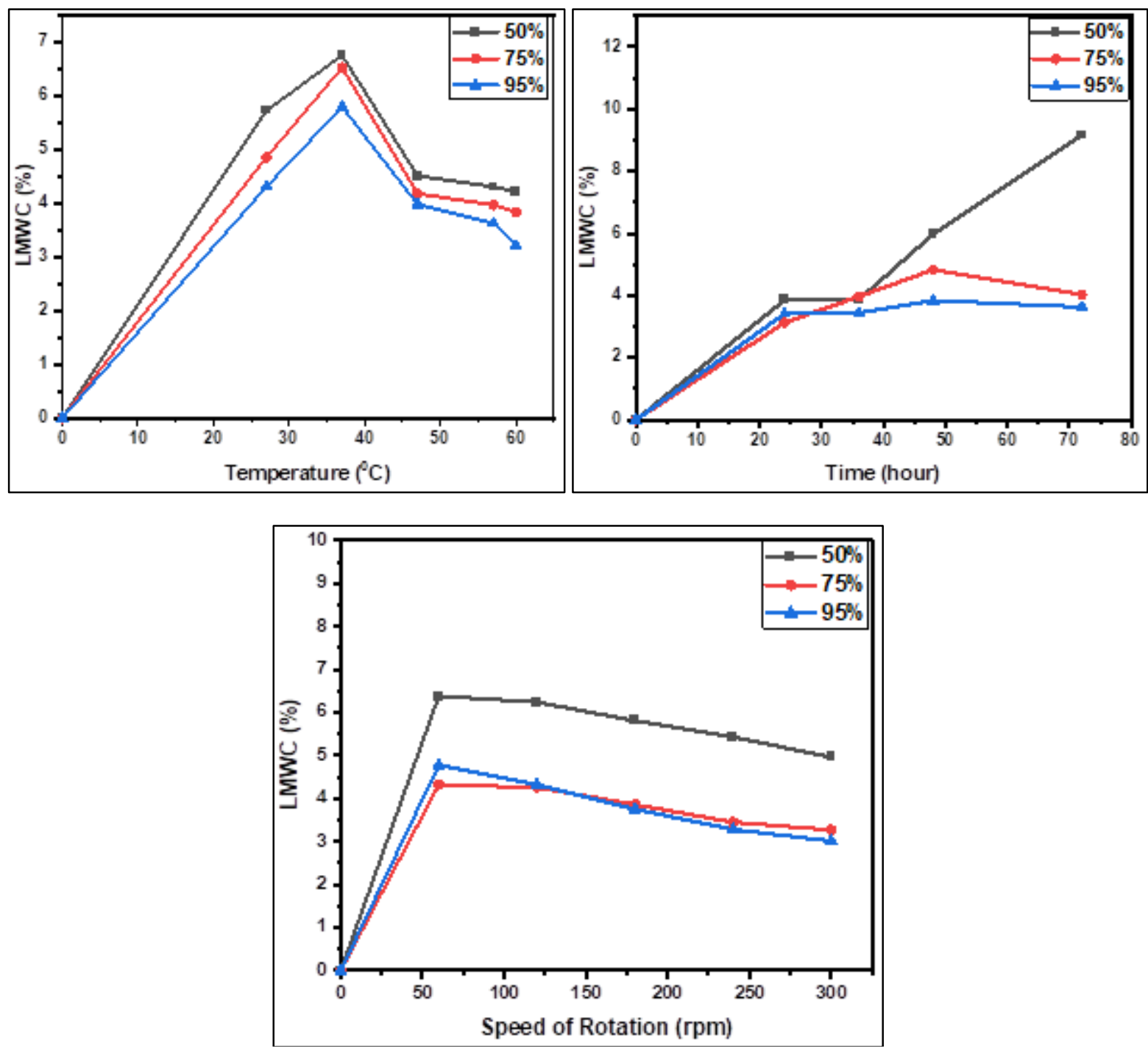

Fig 1: Effect of different treatment conditions on the yield of LMWC Temperature $\left({ }^{\circ} \mathrm{C}\right)(\mathrm{b})$ Time(h) (c) Speed of rotation(rpm)

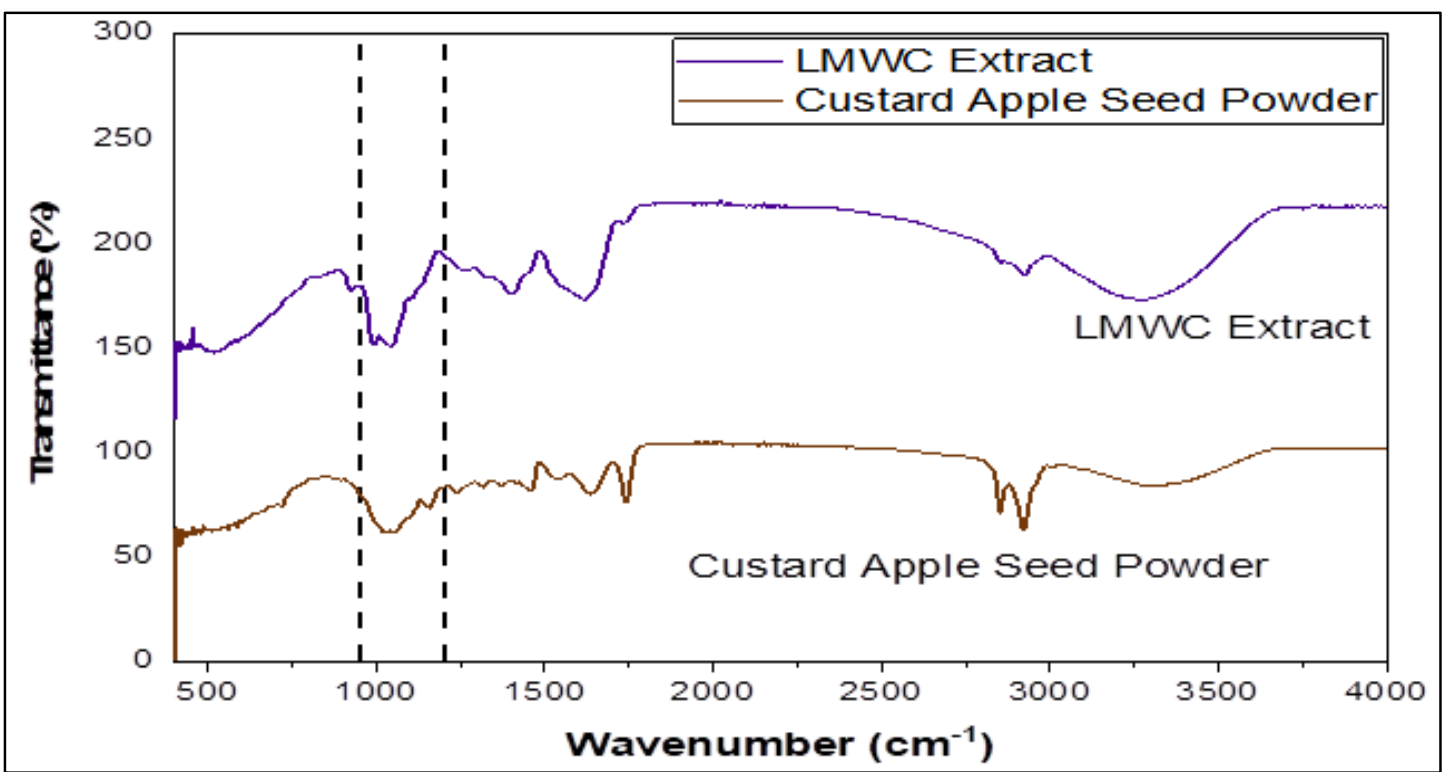

Fig 2: FTIR spectra of Custard Apple Seed powder and LMWC 

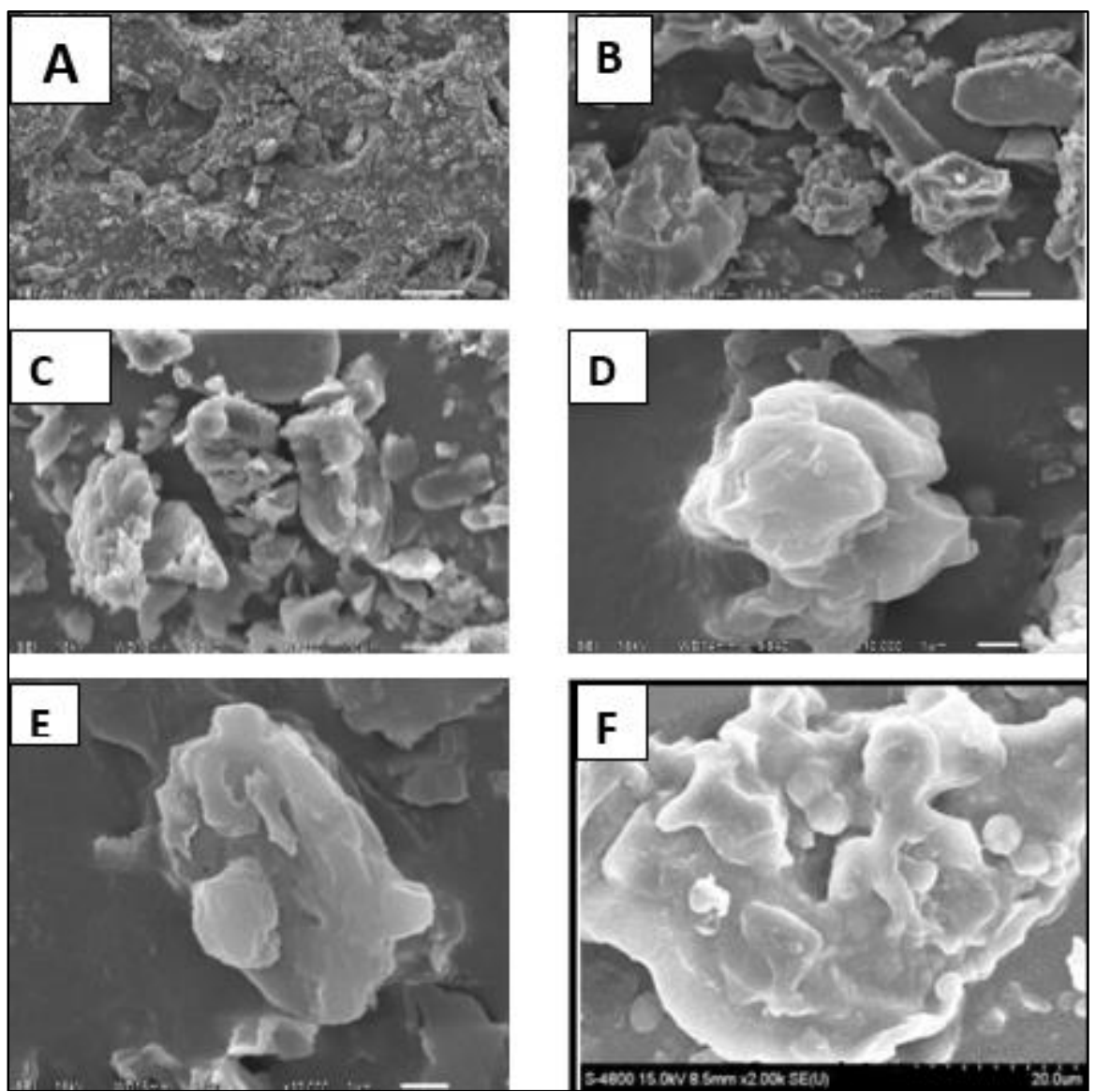

Fig 3: SEM images of Custard Apple Seed Powder under amplication of (A) X150 (B) X700 (C) X1000, LMWC Extract (D) X10000 (E) $\mathrm{X} 12000$ (F) X20000

Table 1: Physico-chemical properties of Custard Apple Seeds

\begin{tabular}{|c|c|}
\hline Parameter & Mean \pm SD \\
\hline Moisture (\%) & $28.73 \pm 0.04$ \\
\hline Total Fat (\%) & $15.17 \pm 0.05$ \\
\hline Crude fiber (\%) & $27.78 \pm 0.06$ \\
\hline Total Ash Content (\%) & $1.75 \pm 0.15$ \\
\hline Acid Insoluble Ash (\%) & $0.16 \pm 0.08$ \\
\hline Protein (\%) & $11.97 \pm 0.02$ \\
\hline Carbohydrates (by difference) (\%) & $14.26 \pm 0.06$ \\
\hline $\mathrm{a}_{\mathrm{w}}$ & $0.26 \pm 0.02$ \\
\hline $\mathrm{L}^{*}$ & $52.21 \pm 0.03$ \\
\hline $\mathrm{a}^{*}$ & $6.58 \pm 0.01$ \\
\hline $\mathrm{b}^{*}$ & $20.24 \pm 0.02$ \\
\hline Swelling capacity (\%) & $5.0 \pm 0.04$ \\
\hline Bulk Density (g/cm $\left.{ }^{3}\right)$ & $0.5 \pm 0.02$ \\
\hline Water Absorption capacity (\%) & $201.2 \pm 0.05$ \\
\hline Oil Absorption Capacity (\%) & $160.95 \pm 0.03$ \\
\hline Emulsion Capacity (\%) & $40.00 \pm 0.02$ \\
\hline Foaming Capacity (\%) & $4.44 \pm 0.04$ \\
\hline
\end{tabular}

Table 2: Yield of LMWC from Custard Apple seed powder under different experimental conditions

\begin{tabular}{|c|c|c|c|c|c|}
\hline \multirow{3}{*}{ Run } & \multicolumn{4}{|c|}{ Formulation Variables } & \multirow{3}{*}{ Yield of LMWC (\%) } \\
\hline & Factor 1 & Factor 2 & Factor 3 & Factor 4 & \\
\hline & Ethanol (\%) & Temperature $\left({ }^{0} \mathrm{C}\right)$ & Time (h) & Speed of rotation (rpm) & \\
\hline 1 & 95 & 30 & 36 & 60 & $4.78 \pm 0.02$ \\
\hline 2 & 75 & 60 & 48 & 240 & $3.67 \pm 0.04$ \\
\hline 3 & 75 & 50 & 48 & 120 & $3.97 \pm 0.03$ \\
\hline 4 & 75 & 30 & 36 & 240 & $4.83 \pm 0.04$ \\
\hline 5 & 50 & 50 & 36 & 180 & $5.81 \pm 0.02$ \\
\hline 6 & 50 & 60 & 72 & 240 & $4.93 \pm 0.01$ \\
\hline 7 & 75 & 40 & 24 & 120 & $3.99 \pm 0.03$ \\
\hline 8 & 95 & 40 & 72 & 120 & $4.53 \pm 0.06$ \\
\hline 9 & 75 & 60 & 72 & 60 & $3.64 \pm 0.03$ \\
\hline 10 & 75 & 40 & 48 & 60 & $4.32 \pm 0.01$ \\
\hline
\end{tabular}




\begin{tabular}{|c|c|c|c|c|c|}
\hline 11 & 50 & 60 & 48 & 180 & $6.32 \pm 0.02$ \\
\hline 12 & 50 & 50 & 48 & 60 & $6.38 \pm 0.02$ \\
\hline 13 & 95 & 50 & 48 & 180 & $3.84 \pm 0.03$ \\
\hline 14 & 95 & 40 & 48 & 240 & $3.63 \pm 0.07$ \\
\hline 15 & 95 & 60 & 48 & 120 & $3.42 \pm 0.04$ \\
\hline 16 & 95 & 30 & 36 & 180 & $4.12 \pm 0.01$ \\
\hline 17 & 75 & 60 & 36 & 120 & $2.76 \pm 0.03$ \\
\hline 18 & 75 & 40 & 36 & 180 & $3.14 \pm 0.02$ \\
\hline 19 & 75 & 50 & 36 & 60 & $3.97 \pm 0.01$ \\
\hline 20 & 95 & 50 & 72 & 60 & $5.23 \pm 0.02$ \\
\hline 21 & 95 & 50 & 24 & 240 & $3.62 \pm 0.02$ \\
\hline 22 & 75 & 50 & 24 & 180 & $3.32 \pm 0.01$ \\
\hline 23 & 75 & 30 & 36 & 120 & $3.41 \pm 0.03$ \\
\hline 24 & 75 & 60 & 24 & 180 & $3.79 \pm 0.04$ \\
\hline 25 & 95 & 60 & 36 & 240 & $3.21 \pm 0.05$ \\
\hline 26 & 50 & 40 & 36 & 240 & $5.94 \pm 0.02$ \\
\hline 27 & 75 & 40 & 24 & 240 & $3.13 \pm 0.03$ \\
\hline 28 & 95 & 50 & 36 & 120 & $3.74 \pm 0.02$ \\
\hline 29 & 50 & 30 & 24 & 240 & $3.86 \pm 0.04$ \\
\hline 30 & 50 & 30 & 48 & 120 & $4.97 \pm 0.02$ \\
\hline 31 & 75 & 40 & 72 & 60 & $4.35 \pm 0.01$ \\
\hline 32 & 50 & 30 & 24 & 180 & $3.12 \pm 0.04$ \\
\hline 33 & 95 & 30 & 72 & 240 & $4.36 \pm 0.05$ \\
\hline 34 & 50 & 60 & 36 & 60 & $3.87 \pm 0.02$ \\
\hline 35 & 95 & 60 & 24 & 60 & $4.87 \pm 0.03$ \\
\hline 36 & 50 & 40 & 48 & 180 & $3.98 \pm 0.01$ \\
\hline 37 & 95 & 30 & 48 & 60 & $4.98 \pm 0.02$ \\
\hline 38 & 75 & 40 & 72 & 240 & $3.25 \pm 0.04$ \\
\hline 39 & 50 & 40 & 72 & 180 & $3.99 \pm 0.03$ \\
\hline 40 & 95 & 40 & 24 & 180 & $3.64 \pm 0.02$ \\
\hline 41 & 95 & 40 & 36 & 60 & $4.23 \pm 0.04$ \\
\hline 42 & 75 & 30 & 48 & 180 & $3.62 \pm 0.03$ \\
\hline 43 & 75 & 30 & 72 & 180 & $3.76 \pm 0.02$ \\
\hline 44 & 50 & 30 & 72 & 60 & $9.16 \pm 0.03$ \\
\hline 45 & 50 & 50 & 36 & 240 & $4.31 \pm 0.04$ \\
\hline 46 & 95 & 60 & 72 & 180 & $4.29 \pm 0.03$ \\
\hline 47 & 75 & 60 & 72 & 120 & $4.35 \pm 0.05$ \\
\hline 48 & 50 & 30 & 36 & 120 & $4.32 \pm 0.02$ \\
\hline 49 & 50 & 50 & 72 & 120 & $3.75 \pm 0.03$ \\
\hline 50 & 50 & 40 & 36 & 120 & $3.24 \pm 0.01$ \\
\hline 51 & 75 & 50 & 48 & 240 & $3.02 \pm 0.02$ \\
\hline 52 & 75 & 30 & 24 & 60 & $5.03 \pm 0.03$ \\
\hline 53 & 75 & 50 & 72 & 180 & $4.02 \pm 0.02$ \\
\hline 54 & 50 & 60 & 24 & 120 & $3.63 \pm 0.04$ \\
\hline 55 & 50 & 40 & 24 & 60 & $3.71 \pm 0.03$ \\
\hline 56 & 95 & 30 & 24 & 120 & $3.01 \pm 0.02$ \\
\hline 57 & 50 & 50 & 24 & 60 & $3.25 \pm 0.04$ \\
\hline
\end{tabular}

Table 3: Bacterial Growth in the Carbohydrate Fractions of LMWC $(\log \mathrm{cfu} / \mathrm{ml})$

\begin{tabular}{|c|c|c|c|c|}
\hline \multirow{2}{*}{ Carbohydrates } & \multicolumn{2}{|c|}{$\begin{array}{c}\text { Lactobacillus } \\
\text { bulgaricus }\end{array}$} & \multicolumn{2}{c|}{$\begin{array}{c}\text { Staphylococcus } \\
\text { aureus }\end{array}$} \\
\cline { 2 - 5 } & $0 \mathrm{~h}$ & $24 \mathrm{~h}$ & $0 \mathrm{~h}$ & $24 \mathrm{~h}$ \\
\hline LMWC & 0 & $0.98 \pm 0.03$ & 0 & $0.61 \pm 0.04$ \\
\hline Glucose* (Standard) & 0 & $1.51 \pm 0.04$ & 0 & $1.08 \pm 0.04$ \\
\hline
\end{tabular}

*Growth on Glucose was used as a standard for reference

\section{Conclusion}

This work was done to identify and extract the components in the custard apple seeds with potential prebiotic activity. Among the different components, the low molecular weight carbohydrates (LMWC) were selected for the study and extracted using eco-friendly techniques. The yield obtained was more with $50 \%$ Ethanol, $37^{\circ} \mathrm{C}$ Temperature, 72 hours and $60 \mathrm{rpm}$. The positive prebiotic activity score suggested that LMWC are capable of improving the growth of potential probiotic microorganisms. Development of robust, economical and automated methods for the utilization of Custard Apple Seeds as an ingredient in food processing and Probiotic formulations will be an added advantage both for the farmers and also the food industry. Effective utilization of the Custard Apple seeds will pave a way for the waste to wealth concept and the prebiotics extracted from the seeds can be used as an ingredient for functional foods, nutraceuticals and health foods formulations.

\section{Acknowledgement}

I sincerely acknowledge to all the staffs of Department of Food Safety and Quality Testing and Department of Food Biotechnology for their assistance and Co-operation throughout the work.

\section{References}

1. Černá M, Barros AS, Nunes A, Rocha SM, Delgadillo I, Čopiková J, et al. Use of FT-IR spectroscopy as a tool for the analysis of polysaccharide food additives. Carbohydrate Polymers 2003;51(4):383-389. 
2. Fontana Jr AJ, Carter BP. Measurement of Water Activity, Moisture Sorption Isotherm, and Moisture Content of Foods. Water Activity in Foods: Fundamentals and Applications 2020, 207-226.

3. Fooks LJ, Gibson GR. In vitro investigations of the effect of probiotics and prebiotics on selected human intestinal pathogens. FEMS Microbiology Ecology 2002;39(1):6775.

4. Gibson GR, Roberfroid MB. Dietary modulation of the human colonic microbiota: introducing the concept of prebiotics. The Journal of Nutrition 1995;125(6):14011412.

5. Hartmann M, Palzer S. Caking of amorphous powders Material aspects, modelling and applications. Powder Technology 2011;206(1-2):112-121.

6. Huebner J, Wehling RL, Hutkins RW. Functional activity of commercial prebiotics. International Dairy Journal 2007;17(7):770-775.

7. Jamkhande PG, Wattamwar AS. Annona reticulata Linn.(Bullock's heart): Plant profile, phytochemistry and pharmacological properties. Journal of Traditional and Complementary Medicine 2015;5(3):144-152.

8. Jamkhande PG, Wattamwar AS, Pekamwar SS, Chandak PG. Antioxidant, antimicrobial activity and in silico PASS prediction of Annona reticulata Linn. root extract. Beni-Suef University Journal of Basic and Applied Sciences 2014;3(2):140-148.

9. Jork H. Thin-layer chromatography: reagents and detection methods (Vol. 1). Wiley-VCH 1994.

10. Lokhande AR, Patil VS, Wani KS. Study of diethanolamide from Custard apple seed oil (Annonasquamosa L.). International Journal of Engineering Research \& Technology 2013;2(9):448-452.

11. Malathi V, Devegowda G. In vitro evaluation of nonstarch polysaccharide digestibility of feed ingredients by enzymes. Poultry Science 2001;80(3):302-305.

12. Maldonado-Valderrama $J$, Wilde $P$, Macierzanka A, Mackie A. The role of bile salts in digestion. Advances in Colloid and Interface Science 2011;165(1):36-46.

13. Matsuhiro B, Torres R, Zúñiga EA, Aguirre MJ, Mendoza L, Isaacs $\mathrm{M}$, et al. Determination of low molecular weight carbohydrates in cabernet sauvignon red wines. Journal of the Chilean Chemical Society 2009;54(4):405-407.

14. Miller GL. Use of dinitrosalicylic acid reagent for determination of reducing sugar. Analytical Chemistry 1959;31(3):426-428.

15. Moongngarm A, Trachoo N, Sirigungwan N. Low molecular weight carbohydrates, prebiotic content, and prebiotic activity of selected food plants in Thailand. Adv J Food Sci Technol 2011;3(4):269-274.

16. Morton J. Banana. Fruits of warm climates (pp. 29--46). Miami FL: Julia F. Morton. Mukwa LFT, Muengula M, Zinga I, Kalonji A, Iskra-Caruana ML, Bragard C (2014) Occurrence and distribution of banana bunchy top virus related agro-ecosystem in south western, Democrat. Am J Plant Sci 1987;5:647-658.

17. $\mathrm{Mu} \mathrm{Y}, \mathrm{Yu} \mathrm{HQ}$, Wang $\mathrm{Y}$. The role of $\mathrm{pH}$ in the fermentative $\mathrm{H} 2$ production from an acidogenic granulebased reactor. Chemosphere 2006;64(3):350-358.

18. Nair SS, Kavrekar V, Mishra A. In vitro studies on alpha amylase and alpha glucosidase inhibitory activities of selected plant extracts. European Journal of Experimental Biology 2013;3(1):128-132.
19. Neumann H, Zehavi U, Tanksley TD. Acid labile sugar in pepsinogen. Biochemical and Biophysical Research Communications 1969;36(1):151-155.

20. Pallavi JK, Arcot J, Antony U. Prebiotic efficiency of custard apple seeds. International Journal of Innovative Science and Research Technology 2017;2(7):162-168.

21. Parate VR, Waghrulkar SS, Talib MI. Utilization of Custard Apple (Annona squamosa) Seeds for Heavy Metal (Ni (II)) Removal. Methods 1986, 11.

22. Scholz-Ahrens KE, Ade P, Marten B, Weber P, Timm W, Avarsigmail $\mathrm{Y}$, et al. Prebiotics, probiotics, and synbiotics affect mineral absorption, bone mineral content, and bone structure. The Journal of Nutrition 2007;137(3):838S-846S.

23. Scholz-Ahrens KE, Schaafsma G, Van den Heuvel EGHM, Schrezenmeir J. Effects of prebiotics on mineral metabolism. The American Journal of Clinical Nutrition 2001;73(2):459s-464s.

24. Shaltout AA, Allam MA, Moharram MA. FTIR spectroscopic, thermal and XRD characterization of hydroxyapatite from new natural sources. Spectrochimica Acta Part A: Molecular and Biomolecular Spectroscopy 2011;83(1):56-60.

25. Shardul K, Swati J, Prajakta K, Prafullachandra T, Santosh P, Arun R, et al. Proximate analysis of peel and seed of Annona squamosa (Custard apple) fruit. Research Journal of Chemical Sciences 2013. ISSN, 2231, 606X.

26. Sreenath HK. Studies on starch granules digestion by \$ $\alpha$-amylase. Starch-Stärke 1992;44(2):61-63.

27. Tan LW, Ibrahim MN, Kamil R, Taip FS. Empirical modeling for spray drying process of sticky and nonsticky products. Procedia Food Science 2011;1:690-697.

28. White GW, Cakebread SH. The glassy state in certain sugar-containing food products. International Journal of Food Science \& Technology 1966;1(1):73-82.

29. Wichienchot $S$, Thammarutwasik $P$, Jongjareonrak A, Chansuwan W, Hmadhlu P, Hongpattarakere T, et al. Extraction and analysis of prebiotics from selected plants from southern Thailand. Songklanakarin Journal of Science \& Technology 2011;33(5).

30. Yadav SA, Gite SS, Lanjekar VB, Nilegaonkar SS, Agte VV. In vitro screening of indigenous plant materials for prebiotic potential. International Journal of Current Microbiology and Applied Science 2014;3(11):137-150. 